\title{
On the Nature of Suicide-Suicide as a Multipurpose Behaviour Nested in the Human Mind-An Alternative View!
}

\author{
Lars Jacobsson \\ Department of Clinical Sciences, Psychiatry, Umeå University, Umeå, Sweden \\ Email: lars.jacobsson@umu.se
}

How to cite this paper: Jacobsson, L. (2018) On the Nature of Suicide-Suicide as a Multipurpose Behaviour Nested in the Human Mind-An Alternative View! Open Journal of Psychiatry, 8, 137-141. https://doi.org/10.4236/ojpsych.2018.82013

Received: January 23, 2018

Accepted: April 20, 2018

Published: April 23, 2018

Copyright $\odot 2018$ by author and Scientific Research Publishing Inc. This work is licensed under the Creative Commons Attribution International License (CC BY 4.0).

http://creativecommons.org/licenses/by/4.0/

Open Access

\begin{abstract}
Suicide is a universal human phenomenon and seems to be a multipurpose behaviour which occurs in a number of different situations that not necessarily have to do with mental distress/disorder. It might as well be a kind of defence of a threatened self-image or revenge or punishment or weapon in a struggle for something more important than the own life. Is there a suicidal virus or meme nested in the human mind? Maybe it is the mere idea of suicide as an alternative way of dealing with a number of human dilemmas that should be the focus of our suicide preventive efforts? Suicide ideas are common in most populations, but ideas are just ideas. It is when the ideas-the suicidal thoughts-are converted to actions that they become dangerous. The focus for our suicide preventive work should be to counteract a destructive use of suicidal ideation. So, the crucial question is thus: how do we do that?
\end{abstract}

\section{Keywords}

Suicide, Suicide Prevention, Suicidal Behaviour, Meme, Memeology, Suicidal Mode

\section{Suicide-Not Just a Matter of Mental Illness!}

Suicide has followed humanity as long as we know anything about human life. The prevalence has varied over time and circumstances. Mostly suicide has been condemned, but sometimes even seen as something praiseworthy or at least acceptable. In modern times, it has been seen as a public health problem and necessary to treat and even better prevent. The World Health Organization (WHO) has developed strategies for suicide prevention and many countries, especially in the western world, have also developed special plans for treatment and preven- 
tion [1]. The best basis for such an endeavour is a thorough understanding of the nature of suicide-why suicide? The cause/s has been sought in numerous studies all over the world resulting in a number of theories, models and risk factors [2]. Most researchers agree that suicide is a complex issue. Durkheim and other sociologists have seen suicide as a consequence of social processes [3]. Others have pointed at psychic pain as a driving force [4]. A recent perspective has been to see suicide as a process sometimes starting early in life and finally ending up in a completed suicide in some cases (one million per year according to WHO) [5]. The prevailing idea, especially in western settings now, is to look at suicide as a consequence of mental illness, especially depression and anxiety often referred to as a medicalization of suicide. Research has accordingly focused on risk factors and a number of such have been identified; social, psychiatric and biologic including genetic factors [2]. There is also, however, criticism against this "medicalization" of the suicide issue [6].

However, no one of all these models have departed from the basic question why humans at all have developed suicide as a possible "solution" when life for apparently a number of reasons is experienced as impossible to handle. But not only that-suicide has also been used as a means for revenge and punishment, but also as a weapon in a fight for something considered even more valuable than the personal life, for example in a political struggle. Looking globally suicide is really a multipurpose behaviour possible to "use" depending on a lot of different socio-culturally bound circumstances.

\section{An Alternative View—Suicidal Modes and Memes}

Freud proposed the possibility of some kind of death instinct without giving more explicit details on the idea [7]. Suicide cannot be understood without the occurrence of a self-destructive process, which can start very early in life and go on for many years ("chronic suicidality"). Rudd talks about suicide as a consequence of a suicidal mode where affective symptoms, biologic/physiologic factors and a "suicidal belief system" interacts [8].

This "suicidal mode" might have developed in humans during the evolutionary process because of a "survival value" of suicide for the flock/group. All the theories and models mentioned in the introduction can fit into this idea of a survival value of suicide-and-if so, what could that be!? In the extreme case an individual will leave the flock through suicide because of a reduced survival capacity (e.g. serious mental illness or other functional deficits) or a serious conflict with the flock. All the risk factors identified through enormous research efforts, especially in the western world, fit very well into this idea; age, sex, mental illness, family occurrence, alcohol and drugs, genetics, earlier suicidal attempts ... All these will fit into the idea of a suicidal complex which in the end is based on some kind of a "suicidal mode" inherent in the human nature.

Is there a "suicidal virus" nested into the human genome or maybe there is a suicidal "meme" according to Richard Dawkins [9]. According to the Oxford 
dictionary the definition of a "meme" is as follows; "an element of a culture system of behaviour passed from one individual to another by imitation or other non-genetic means". According to Dawkins memeology memes are information carriers, reproducing themselves in an evolutionary way and spread between brains through copying or imitation. The brain might function as substrate or host for these ideas.

Ideas are apparently very contagious. The idea of suicide is spread globally, but also apparently with a varying prevalence in different cultural settings. In Sweden and probably in most western countries most people are familiar with suicidal thoughts. There are a number of studies showing that quite a number of the population admit having or having had ideas of suicide as a possibility. Ovuga, for example, reports of a life time prevalence of suicidal ideation in Uganda of 36.1\% [10]. Kaiser and Salander Renberg found suicidal ideation in northern Sweden to be $23.6 \%$ - 27.4\% (Swedish population and Sami population) [11]. Ghazinour et al. report on death wishes in $67.4 \%$ and suicidal ideation in $34.6 \%$ in Iranian Kurds [12]. In most cases people are just carriers of the idea of suicide and only a minority are making attempts and an even smaller minority do finally commit suicide. However, one million per year globally is on the other hand quite a big number-much higher than the number of people killed in wars and criminal cases.

\section{Suicide Prevention}

So, what would such an approach to suicide mean to our way of looking at suicide and the efforts to prevent suicide. If the mere idea of committing suicide is something inherent in the human nature, what can we do!? There are many reasons to try to prevent suicide. We have for long tried to override the natural selection of the fittest in our society, so even if there is a suicidal mode built into human nature there are many good reasons to try to find other solutions to the situations that are perceived as impossible to stand by the suicidal person. There are almost always alternatives to suicide when looked at the situation from outside. Mental disorders can be treated, serious somatic pain can be relieved, loneliness can be changed, loss of loved ones can be handled, political conflicts can be solved by other means, personal revenge and punishment are possible to deal with other ways.

On a society level it is probably more important to spread the message that there are other alternatives to suicide when life is experienced hopeless for different reasons and to make these alternatives visible and more easily available. The reasons for thinking of suicide and committing suicide are different in different socio-cultural settings and it should be a primary task to investigate the role of suicide in the different socio-cultural settings.

There are also a number of studies looking into the perceived background of suicide. People in general refer to economic problems, love affairs, family discord and long term serious illness. Mental illness is usually not coming high up 
on these lists [13] [14]. It is interesting that these findings seldom are focused in the suicide prevention programs developed worldwide [1].

In the western part of the world mental disorders are apparently strongly connected to suicide and in this setting identification and treatment of mental disorders will be important, but not the most important thing, because there is no direct causality between mental illness and suicide [6]. The role of mental illness in our context is probably that mental disorders decrease a person's ability to handle life and the very idea of suicide must be the primary target for suicide prevention. Research should thus be directed towards how to deal with the idea of suicide instead of all the identified suicidal risk factors.

Our role as professionals and relatives and friends of suicidal persons would be to act as "agents of hope"-to show that change is possible. Maybe the suicidal mode is not necessarily a longing for death, probably it is more a longing away from conflicts, a longing for peace and maybe in the end a longing for the paradise. The myth about the peaceful paradise seems also to be a universal idea appearing in most religions and world views of different cultures-maybe the paradise myth is just another cultural meme [15].

The multitude of theories and models and reasoning about suicide has not helped us very much in our practical work with suicide prevention and to support suicidal persons. Maybe it is time to accept the simple fact that suicide is a multipurpose behaviour, most often a way of solving serious conflicts, intrapersonal, interpersonal and/or societal. In the single cases of suicidal persons, we have to discuss alternative solutions with respect for the suicidal persons' strategy as not necessarily an expression of weakness or mental illness.

The fact that the suicide rate has gone down in most western countries during the last decades, maybe is just an effect of the increased interest in suicide prevention and not so much because of all the prevention programs developed. The basic issue to address is the existential question about the meaning of life and how to deal with the challenges of life that encounter all of us. This will vary from individual to individual depending on personal and cultural differences. You may very well think about suicide, but avoid doing it—-there are other possibilities!

And how do we deal with potentially dangerous ideas!? First of all it is necessary to accept as a fact that suicidal ideas are part of being humans and not necessarily something that should be regarded as "unnatural", a sign of weakness, illness, immorality ... Suicidal ideas are just ideas-potentially dangerous if converted into action. For most people the idea of suicide is a comforting idea. It tells about the possible escape if life becomes too demanding for many different reasons, but also as a tool for accomplishing something considered even more valuable than life.

\section{Conclusion}

What we should focus on in our prevention efforts is the destructive "use" of the 
"suicidal mode". Suicidal acts should be regarded as signs of threat and danger and be analyzed to find out what has become wrong, intolerable in the life of the haunted individual and the society at large especially in societies with high suicidal rates. In this search for what's wrong, all the "risk factors" identified are of interest to try to approach and counteract as much as possible. But still it is the mere idea of suicide as the "solution" of the problem at stake that must be the primary target. You might very well think about suicide, but don't do it-there are other possibilities-let us talk about these!

\section{References}

[1] World Health Organization (2014) Preventing Suicide: A Global Imperative. Geneva.

[2] Wasserman, D. and Dunitz, M. (Eds.) (2001) Suicide-An Unnecessary Death.

[3] Durkheim, E. (1992) Suicide. Routledge, London.

[4] Shneidman, E.S. (1993) Suicide as Psychache. A Clinical Approach to Self-Destructive Behaviour. Rowman \& Littlefield Publishers, Lanham.

[5] Wasserman, D. (2001) A Stress-Vulnerability Model and the Development of the Suicidal Process. In: Wasserman, D., Ed., Suicide-An Unnecessary Death, Marlin Dunitz, 13-27.

[6] Hjelmeland, H. and Knizek, B.L. (2017) Suicide and Mental Disorders: A Discourse of Politics, Power and Vested Interests. Death Studies, 41, 481-492. https://doi.org/10.1080/07481187.2017.1332905

[7] Freud, G.P. (1988) A Life for Our Time. WW Norton \& Co. Ltd., New York-London.

[8] Rudd, M.D. (2000) The Suicidal Mode: A Cognitive-Behavioral Model of Suicidality. Suicide and Life-Threatening Behavior, 30, 18-33.

[9] Dawkins, R. (1989) The Selfish Gene. Oxford University Press, Oxford.

[10] Ovuga, E., Boardman, J. and Wasserman, D. (2005) Prevalence of Suicide Ideation in Two Districts of Uganda. Archives of Suicide Research, 9, 321-332. https://doi.org/10.1080/13811110500182018

[11] Kaiser, N. and Salander Renberg, E.S. (2012) Suicidal Expressions among the Swedish Reindeer Herding Sami Population. Suicidology Online, No. 3, 102-113.

[12] Ghazinour, M., Richter, J. and Mofidi, N. (2010) Continuity from Suicidal Ideation to Suicide Attempts. An Investigation in 18-55 Years Old Adult Iranian Kurds. Social Psychiatry and Psychiatric Epidemiology, 45, 973-981. https://doi.org/10.1007/s00127-009-0136-z

[13] Mugisha, J., Hjelmeland, H., Kinyanda, E. and Knizek, B.L. (2014) The Internal Dialogue between the Individual and the Community: A Discourse Analysis of Public Views on Suicide and the Community. International Journal of Culture and Mental Health, 7, 122-136. https://doi.org/10.1080/17542863.2012.732589

[14] Herrera, A., Caldera, T., Kullgren, G., Pena, R. and Salander Renberg, E. (2006) Suicidal Expressions among Young People in Nicaragua: A Community Based Study. Social Psychiatry and Epidemiology, 41, 692-697. https://doi.org/10.1007/s00127-006-0083-x

[15] Ashton, J. and Whyte, T. (2001) The Quest for Paradise: Visions of Heaven and Eternity in the World's Myths and Religions. Harper San Francisco, 195 Broadway. 